\title{
A valorização do professor no Brasil no contexto das tendências globais
}

\author{
Teachers appreciation in Brazil in global trends context
}

\section{Aline Chalus Vernick Carissimi' Rose Meri Trojan²}

\section{Resumo}

Este trabalho é parte de uma pesquisa situada no âmbito das políticas educacionais sobre as condições de formação e de trabalho do professor. Tem como eixo principal o estudo sobre a valorização profissional docente em diferentes países. Neste sentido, traz um breve panorama mundial sobre o perfil dos professores, considerando a formação inicial e continuada, o salário e as condições de trabalho, de maneira a analisar dados de pesquisas internacionais que permitam identificar as tendências adotadas pelas políticas relacionadas ao trabalho docente no Brasil. Palavras-Chave: Políticas educacionais; Valorização docente; Condições de trabalho.

\begin{abstract}
This work is part of a research situated in the context of educational policies for teachers training and work conditions. The paper has as main axis of the study the teacher professional development in different countries. In this sense, provides a brief overview on the global profile of teachers, considering the initial and continuing training, salary and working conditions in order to analyze data from international research to identify trends adopted by related policies to teaching in Brazil.

Keywords: Educational policies; Teacher appreciation; Work conditions.
\end{abstract}


As perspectivas de melhoria na qualidade do ensino estão articuladas com a valorização docente, traduzida pelas condições concretas de formação, remuneração e de trabalho dos professores. No Brasil, a valorização profissional é proposta pela Constituição Federal (CF) de 1988 (BRASIL, 1988) e ratificada pela Lei de Diretrizes e Bases da Educação Nacional (LDB), Lei nº 9394/1996 (BRASIL, 1996). Entretanto, as mudanças ocorridas no mundo do trabalho e as reformas educacionais, das duas últimas décadas, estabeleceram limites para tal valorização.

As mudanças, que atingiram a maioria dos países no atual contexto de globalização, foram definidoras da agenda política no campo educacional em âmbito internacional. Assim, a proposta de organizar um breve panorama mundial sobre a condição dos professores tem como objetivo situar o Brasil, a partir das políticas implementadas.

Para isso, esse estudo abrange três aspectos: a formação inicial e continuada; a remuneração; e as condições de trabalho, abrangendo hora-atividade, número de alunos por turma, jornada de trabalho e regime de contratação. O panorama é constituído a partir de dados de pesquisas realizadas pela Organização para a Cooperação e Desenvolvimento Econômico (OCDE), e de estudos de Morduchowicz e Duro (2007) e Carnoy, Gove e Marshall (2003).

\section{Formação Inicial e Continuada}

A formação do professor é um dos mecanismos mais importantes para o desenvolvimento da competência docente, e, como afirmam Rodriguez e Vargas(2008, p.37), "as políticas de formação docente nos países da América Latina ganharam centralidade nos projetos educacionais, especialmente, a partir dos anos de 1990." Ainda que seja possível perceber essa centralidade nas políticas implementadas, não é difícil identificar mecanismos de aligeiramento e precariedade nas propostas indicadas.

De acordo com o relatório de 1996 sobre educação para o século XXI, conhecido como relatório Jacques Delors (UNESCO, 2001), no que se refere à formação inicial:

A longo prazo, o objetivo deverá ser fazer com que todos os professores, mas em especial os do secundário, tenham frequentado estudos superiores, sendo a sua formação assegurada em cooperação com as universidades ou mesmo em contexto universitário (UNESCO, 1996, p.159).

Essa indicação posta no relatório é ratificada pela legislação brasileira, elaborada no bojo das reformas educacionais, ao determinar a formação de professores para a educação básica em graduação de nível superior, admitindo a formação em nível médio para os docentes das series iniciais do ensino fundamental, que correspondem ao primário (BRASIL, 1996).

Entretanto, a formação de nível superior, ainda que desejável, não é garantia de qualidade. De acordo com a LDB, são admitidas instituições públicas e privadas com variados graus de abrangência ou especialização (art. 44) e os cursos nas modalidades a distancia ou presencial em diferentes formatos, são autorizados e reconhecidos pelo poder executivo (art. 45) (BRASIL, 1996). Desse modo, as condições das instituições e das propostas de formação, admitidas legalmente, permitem formas extremamente variadas e, consequentemente, de qualidades distintas.

A formação continuada considerada como momento de aperfeiçoamento docente, para a melhoria do processo de ensino e aprendizagem, foi enfatizada no relatório da UNESCO, propondo o desenvolvimento de programas acessíveis e frequentes, ou seja:

Devem ser desencadeados programas que levem os professores a familiarizar-se com os últimos progressos da tecnologia da informação e comunicação. De uma maneira geral, a qualidade de ensino é determinada tanto ou mais pela formação contínua dos professores do que pela sua formação inicial. 0 recurso a técnicas de ensino a distância pode ser uma fonte de economia e permitir que os professores continuem a assegurar o seu serviço, pelo menos em tempo parcial (UNESCO, 2001, p.159).

No entanto, o relatório deixa explícito o caráter pragmático, pois indica que esses mecanismos representam "uma fonte de economia" na capacitação dos professores, revelando a precarização da formação docente.

Ainda assim, o relatório da UNESCO considera que: 0 reforço da formação contínua — dispensada segundo modalidades tão flexíveis quanto possível - pode contribuir muito para aumentar o nível de competência e a motivação dos professores, e melhorar o seu estatuto social (UNESCO, 2001, p.162).

Essa orientação considera que a formação continuada, ao proporcionar desenvolvimento de competências e, sobretudo, a elevação da motivação de preferência em modalidades ou técnicas flexíveis, estará resolvendo o problema do estatuto social dos professores. Desta maneira fica evidente que o discurso da educação de qualidade não destaca a necessidade de mais investimento e ampliação de recursos financeiros, mas somente da melhoria do desempenho docente.

Para avaliar a atual situação da formação inicial e continuada, este estudo se pautará nas informações 
do relatório da pesquisa internacional Teaching and Learning International Survey (Talis), realizada em 2007 (OCDE, 2009). A pesquisa Talis apresenta dados quanto à escolaridade dos professores, considerando o percentual de professores do ensino secundário básico, o que equivale às séries finais do ensino fundamental no Brasil, pelo mais alto nível de ensino formal concluído pelos docentes (tabela1).

Na tabela, é adotada a Classificação Internacional Normalizada da Educação ou International Standard Classification of Education (ISCED) da UNESCO, destinada a permitir a comparação entre diferentes países. De acordo com essa classificação, o nível 5 corresponde à primeira fase da educação terciária, que no Brasil é equivalente ao ensino de nível superior, e está dividido em abaixo da formação superior ou em fase de formação. O nível 5B representa cursos de curta duração e de ordem mais técnica; - nível 5A representa a formação em cursos de graduação; e o nível 6 corresponde à pós-graduação (UNESCO, 1997).

Como é possível perceber, a maior parte da formação docente se concentra no ensino superior (graduação), e neste sentido o Brasil apresenta um percentual bastante significativo de $89,3 \%$, seguido pela formação em nível de especialização, no qual predominam os países europeus.

Isso significa que a reforma educacional empregada no Brasil aponta dados positivos sobre o nível de formação docente, comparado aos demais países pesquisados. No entanto, não é possível afirmar que, de fato, essa formação ocorreu de maneira qualitativa.

Tabela 1 - Escolaridade dos professores (2007-08)

\begin{tabular}{|c|c|c|c|c|c|c|c|c|c|c|}
\hline \multirow[b]{2}{*}{ Países } & \multicolumn{2}{|c|}{$\begin{array}{l}\text { Abaixo da formação supe- } \\
\text { rior ou em formação (5) }\end{array}$} & \multicolumn{2}{|c|}{$\begin{array}{l}\text { Cursos de Curta } \\
\text { Duração (5B) }\end{array}$} & \multicolumn{2}{|c|}{$\begin{array}{c}\text { Cursos de Graduação } \\
\text { (bacharelado) }(5 \AA)\end{array}$} & \multicolumn{2}{|c|}{$\begin{array}{l}\text { Cursos de Graduação } \\
\text { (licenciatura) }(5 A)\end{array}$} & \multicolumn{2}{|c|}{ Pós-Graduação (6) } \\
\hline & $\%$ & (SE) & $\%$ & (SE) & $\%$ & (SE) & $\%$ & (SE) & $\%$ & (SE) \\
\hline Australia & 0,3 & $(0,10)$ & 1,0 & $(0,25)$ & 82,8 & $(0,96)$ & 13,7 & $(0,83)$ & 2,2 & $(0,33)$ \\
\hline Austria & 3,1 & $(0,30)$ & 59,3 & $(0,78)$ & 1,3 & $(0,25)$ & 33,6 & $(0,74)$ & 2,6 & $(0,29)$ \\
\hline Belgium & 3,4 & $(0,38)$ & 84,2 & $(0,96)$ & 4,2 & $(0,42)$ & 8,1 & $(0,73)$ & 0,1 & $(0,07)$ \\
\hline Brazil & 8,6 & $(1,00)$ & 0,2 & $(0,08)$ & 89,3 & $(1,02)$ & 1,8 & $(0,25)$ & 0,1 & $(0,05)$ \\
\hline Bulgaria & 3,7 & $(1,06)$ & 15,7 & $(1,69)$ & 16,4 & $(1,21)$ & 64,0 & $(2,64)$ & 0,2 & $(0,06)$ \\
\hline Denmark & 1,9 & $(0,37)$ & 0,2 & $(0,10)$ & 90,3 & $(1,00)$ & 7,5 & $(0,89)$ & 0,0 & $(0,03)$ \\
\hline Estonia & 7,0 & $(0,51)$ & 6,5 & $(0,46)$ & 40,3 & $(1,15)$ & 46,0 & $(1,21)$ & 0,3 & $(0,11)$ \\
\hline Hungary & 0,2 & $(0,10)$ & 0,1 & $(0,08)$ & 71,5 & $(2,13)$ & 27,8 & $(2,09)$ & 0,4 & $(0,08)$ \\
\hline Iceland & 12,1 & $(0,79)$ & 20,8 & $(1,15)$ & 60,6 & $(1,22)$ & 6,3 & $(0,70)$ & 0,2 & $(0,12)$ \\
\hline Ireland & 0,6 & $(0,20)$ & 3,4 & $(0,33)$ & 79,4 & $(0,70)$ & 15,9 & $(0,78)$ & 0,8 & $(0,19)$ \\
\hline Italy & 5,3 & $(0,30)$ & 9,4 & $(0,42)$ & 6,9 & $(0,37)$ & 77,4 & $(0,58)$ & 0,9 & $(0,19)$ \\
\hline Korea & 0,3 & $(0,11)$ & 0,3 & $(0,14)$ & 64,7 & $(1,39)$ & 33,9 & $(1,35)$ & 0,7 & $(0,16)$ \\
\hline Lithuania & 4,1 & $(0,38)$ & 13,0 & $(0,77)$ & 47,0 & $(1,46)$ & 35,7 & $(1,39)$ & 0,1 & $(0,07)$ \\
\hline Malaysia & 1,0 & $(0,12)$ & 12,1 & $(0,60)$ & 79,4 & $(0,79)$ & 7,5 & $(0,55)$ & 0,0 & $(0,00)$ \\
\hline Malta & 3,7 & $(0,50)$ & 13,3 & $(1,11)$ & 71,9 & $(1,50)$ & 10,7 & $(1,11)$ & 0,4 & $(0,22)$ \\
\hline Mexico & 10,4 & $(0,94)$ & 3,0 & $(0,43)$ & 75,6 & $(1,05)$ & 10,7 & $(0,72)$ & 0,3 & $(0,11)$ \\
\hline Norway & 0,9 & $(0,19)$ & 0,0 & $(0,00)$ & 76,5 & $(0,92)$ & 22,5 & $(0,92)$ & 0,0 & $(0,04)$ \\
\hline Poland & 0,3 & $(0,11)$ & 1,2 & $(0,27)$ & 4,1 & $(0,42)$ & 94,0 & $(0,46)$ & 0,5 & $(0,18)$ \\
\hline Portugal & 0,4 & $(0,11)$ & 4,3 & $(0,43)$ & 84,4 & $(0,76)$ & 10,7 & $(0,71)$ & 0,2 & $(0,09)$ \\
\hline Slovak Republic & 2,5 & $(0,36)$ & 0,0 & $(0,00)$ & 0,5 & $(0,15)$ & 96,2 & $(0,43)$ & 0,8 & $(0,20)$ \\
\hline Slovenia & 3,7 & $(0,34)$ & 41,9 & $(1,04)$ & 52,9 & $(1,05)$ & 1,4 & $(0,20)$ & 0,1 & $(0,04)$ \\
\hline Spain & 3,5 & $(0,35)$ & 1,6 & $(0,22)$ & 11,4 & $(0,85)$ & 78,8 & $(0,89)$ & 4,7 & $(0,41)$ \\
\hline Turkey & 0,0 & $(0,00)$ & 6,0 & $(0,57)$ & 88,2 & $(0,96)$ & 5,6 & $(0,90)$ & 0,2 & $(0,11)$ \\
\hline TALIS Média & 3,4 & $(0,10)$ & 12,9 & $(0,14)$ & 52,1 & $(0,22)$ & 30,9 & $(0,22)$ & 0,7 & $(0,04)$ \\
\hline
\end{tabular}

Fonte: OECD, TALIS Database. 
Já os dados referentes à formação continuada, da pesquisa Talis (tabela 2), indicam o percentual de professores que participaram de desenvolvimento profissional nos últimos 18 meses entre os anos de 2007 e 2008; a média de dias destinados ao aperfeiçoamento para todos os professores; a média de dias entre os que receberam o desenvolvimento profissional; e, o percentual médio de dias em que o desenvolvimento profissional foi obrigatório.

Esses dados permitem identificar os países que investiram em formação continuada tanto no que se refere à abrangência quanto à quantidade de formação ofertada. Entretanto, para avaliar os efeitos desse investimento, é necessário um estudo mais detalhado sobre o conteúdo e a forma dos programas e atividades oferecidas, que não cabem nesse estudo, de caráter preliminar.

Tabela 2. Participação dos professores no desenvolvimento profissional nos últimos 18 meses (2007-08)

\begin{tabular}{|c|c|c|c|c|c|c|c|c|c|c|}
\hline \multirow[b]{2}{*}{ Países } & \multicolumn{2}{|c|}{$\begin{array}{l}\text { Percentagem de } \\
\text { professores que } \\
\text { realizaram algum } \\
\text { desenvolvimento } \\
\text { profissional nos } \\
\text { últimos } 18 \text { meses }\end{array}$} & \multicolumn{3}{|c|}{$\begin{array}{l}\text { Média de dias de } \\
\text { desenvolvimento profissional } \\
\text { para todos os professoresLer } \\
\text { foneticamente }\end{array}$} & \multicolumn{3}{|c|}{$\begin{array}{l}\text { Média de dias de } \\
\text { desenvolvimento profissional } \\
\text { entre aqueles que receberam } \\
\text { alguma }\end{array}$} & \multicolumn{2}{|c|}{$\begin{array}{c}0 \text { percentual } \\
\text { médio de dias de } \\
\text { desenvolvimento } \\
\text { profissional se que } \\
\text { eram obrigatórias }\end{array}$} \\
\hline & $\%$ & (SE) & Média & (SE) & SD & Média & (SE) & SD & Média & (SE) \\
\hline Australia & 96,7 & $(0,43)$ & 8,7 & $(0,19)$ & 7,6 & 9,0 & $(0,20)$ & 7,5 & 47,3 & $(1,17)$ \\
\hline Austria & 96,6 & $(0,37)$ & 10,5 & $(0,17)$ & 9,5 & 10,9 & $(0,16)$ & 9,5 & 31,4 & $(0,66)$ \\
\hline Belgium & 90,3 & $(0,73)$ & 8,0 & $(0,38)$ & 19,6 & 8,8 & $(0,42)$ & 20,5 & 33,6 & $(0,95)$ \\
\hline Brazil & 83,0 & $(1,21)$ & 17,3 & $(0,70)$ & 21,9 & 20,8 & $(0,79)$ & 22,5 & 40,2 & $(1,17)$ \\
\hline Bulgaria & 88,3 & $(1,17)$ & 27,2 & $(1,65)$ & 58,7 & 30,8 & $(2,04)$ & 61,6 & 46,9 & $(2,11)$ \\
\hline Denmark & 75,6 & $(1,26)$ & 9,8 & $(0,34)$ & 14,0 & 12,9 & $(0,40)$ & 14,7 & 34,6 & $(1,43)$ \\
\hline Estonia & 92,7 & $(0,50)$ & 13,1 & $(0,29)$ & 13,7 & 14,2 & $(0,31)$ & 13,7 & 49,2 & $(1,20)$ \\
\hline Hungary & 86,9 & $(1,77)$ & 14,5 & $(0,50)$ & 16,2 & 16,7 & $(0,41)$ & 16,3 & 46,1 & $(1,58)$ \\
\hline Iceland & 77,1 & $(1,10)$ & 10,7 & $(0,44)$ & 14,7 & 13,9 & $(0,56)$ & 15,3 & 49,9 & $(1,30)$ \\
\hline Ireland & 89,7 & $(0,78)$ & 5,6 & $(0,21)$ & 8,0 & 6,2 & $(0,21)$ & 8,2 & 41,4 & $(0,99)$ \\
\hline Italy & 84,6 & $(0,76)$ & 26,6 & $(0,98)$ & 45,6 & 31,4 & $(1,17)$ & 48,0 & 40,0 & $(1,08)$ \\
\hline Korea & 91,9 & $(0,59)$ & 30,0 & $(0,57)$ & 26,0 & 32,7 & $(0,55)$ & 25,5 & 46,9 & $(0,85)$ \\
\hline Lithuania & 95,5 & $(0,40)$ & 11,2 & $(0,21)$ & 10,2 & 11,8 & $(0,21)$ & 10,1 & 56,6 & $(0,98)$ \\
\hline Malaysia & 91,7 & $(0,67)$ & 11,0 & $(0,32)$ & 11,0 & 11,9 & $(0,33)$ & 11,0 & 88,1 & $(0,64)$ \\
\hline Malta & 94,1 & $(0,75)$ & 7,3 & $(0,25)$ & 7,4 & 7,8 & $(0,26)$ & 7,4 & 78,4 & $(1,07)$ \\
\hline Mexico & 91,5 & $(0,60)$ & 34,0 & $(1,60)$ & 65,2 & 37,1 & $(1,78)$ & 67,3 & 66,4 & $(1,22)$ \\
\hline Norway & 86,7 & $(0,87)$ & 9,2 & $(0,30)$ & 13,4 & 10,6 & $(0,34)$ & 13,9 & 55,5 & $(1,25)$ \\
\hline Poland & 90,4 & $(0,67)$ & 26,1 & $(1,10)$ & 44,1 & 28,9 & $(1,20)$ & 45,5 & 41,0 & $(1,14)$ \\
\hline Portugal & 85,8 & $(0,87)$ & 18,5 & $(0,89)$ & 39,0 & 21,6 & $(1,01)$ & 41,3 & 35,1 & $(0,99)$ \\
\hline $\begin{array}{c}\text { Slovak } \\
\text { Republic }\end{array}$ & 75,0 & $(1,13)$ & 7,2 & $(0,30)$ & 9,8 & 9,6 & $(0,38)$ & 10,2 & 44,1 & $(1,19)$ \\
\hline Slovenia & 96,9 & $(0,35)$ & 8,3 & $(0,20)$ & 8,2 & 8,6 & $(0,20)$ & 8,2 & 60,5 & $(0,93)$ \\
\hline Spain & 100,0 & $(0,03)$ & 25,6 & $(0,51)$ & 19,3 & 25,6 & $(0,51)$ & 19,3 & 66,8 & $(0,99)$ \\
\hline Turkey & 74,8 & $(2,09)$ & 11,2 & $(0,52)$ & 14,9 & 14,9 & $(0,65)$ & 15,5 & 72,8 & $(1,65)$ \\
\hline $\begin{array}{l}\text { TALIS } \\
\text { Média }\end{array}$ & 88,5 & $(0,20)$ & 15,3 & $(0,14)$ & 21,7 & 17,3 & $(0,16)$ & 22,3 & 51,0 & $(0,25)$ \\
\hline
\end{tabular}

Fonte: OECD, TALIS Database. 
Os números indicam que a maior parte dos docentes (88,5\%) participou de algum programa de desenvolvimento profissional nos últimos 18 meses, que demonstram, de maneira geral, uma tendência de investimento na formação continuada. No Brasil, $83 \%$ dos docentes afirmaram ter participado de formação continuada, dado que apresenta um percentual bastante significativo, que deve impactar na qualidade do fazer pedagógico. Entretanto, não se pode deixar de mencionar o fato de que $11,5 \%$ dos professores não usufruem do que deveria ser reconhecido como direito e dever profissional, reconhecida a importância da formação continuada.

\section{Salário}

A remuneração também representa um aspecto fundamental do perfil profissional nas redes de ensino, e demonstra, em alguma medida, a valorização profissional proporcionada, ou seja, revela o reconhecimento pelo trabalho desenvolvido pelo professor.

Para Marques e Abud (2008, p. 51) "entende-se por remuneração o conjunto de prestações recebidas pelo empregado em razão da prestação de serviços, em dinheiro ou utilidades, proveniente dos empregadores ou de terceiros". O valor da remuneração revela o nível de reconhecimento do serviço prestado, mas, "quando se fala em valorização salarial, contudo, há que se ter claro, de que a medida não é, necessariamente, um valor muito acima, mas, simples e tão somente, o que já é pago por outras profissões" (PINTO, 2009, p.60).

Nesse sentido, afirma-se que a profissão docente sofre certo desprestígio, em relação às demais profissões. É necessário, portanto, investigar como a questão da remuneração, em decorrência da valorização salarial, é tratada enquanto política, já que a melhoria das condições de trabalho docente perpassa por essas medidas.
$\mathrm{Na}$ pesquisa "La Inversión Educativa en América Latina y el Caribe e Education at a Glance" (Morduchowicz \& Duro, 2007), que investigou a remuneração de professores, os registros mostram que o Brasil ocupa, entre os países pesquisados, a posição dos que pior pagam seus professores, levando em consideração a relação do valor do dólar em PPP (Poder de Paridade de Compra), conforme a tabela 3.

\section{Tabela 3 - Salários mensais médios (em dólares PPP)}

\begin{tabular}{|c|c|}
\hline País & Valor salarial médio \\
\hline Países da OCDE & $2.310,00$ \\
\hline Colômbia & $1.284,00$ \\
\hline Costa Rica & $1.268,00$ \\
\hline Chile & $1.196,00$ \\
\hline México & 975,00 \\
\hline Argentina & 934,00 \\
\hline Brasil & 892,00 \\
\hline Venezuela & 866,00 \\
\hline
\end{tabular}

Fonte: La Inversión Educativa en América Latina y el Caribe e Education at a Glance 2007. Dados 2005.

Para análise dos valores pagos, é necessário considerar a jornada de trabalho semanal, para isso pode-se observar a tabela 5, conforme dados do estudo citado (MORDUCHOWICZ \& DURO, 2007) a média de trabalho dos professores em 17 países da América Latina é de 37 horas. Os valores pagos no Brasil são para uma jornada de trabalho de 40 horas semanais. 
Tabela 4 - Salários anuais em dólares PPP

\begin{tabular}{|c|c|c|c|}
\hline Países & Salário inicial & Salário após 15 anos & Salário no topo da carreira \\
\hline Australia & 28642 & 42057 & 42057 \\
\hline Austria & 24475 & 32384 & 48977 \\
\hline Belgium (FI.) & 27070 & 37128 & 44626 \\
\hline Belgium (Fr.) & 25684 & 35474 & 42884 \\
\hline Czech Republic & 13808 & 18265 & 23435 \\
\hline Denmark & 32939 & 37076 & 37076 \\
\hline England & 28608 & 41807 & 41807 \\
\hline Finland & 27023 & 31785 & 31785 \\
\hline France & 23106 & 31082 & 45861 \\
\hline Germany & 38216 & 46223 & 49586 \\
\hline Greece & 22990 & 28006 & 33859 \\
\hline Hungary & 11701 & 14923 & 19886 \\
\hline Iceland & 18742 & 21692 & 24164 \\
\hline Ireland & 24458 & 40514 & 45910 \\
\hline Italy & 23751 & 28731 & 34869 \\
\hline Japan & 24514 & 45515 & 57327 \\
\hline Korea & 27214 & 46640 & 74965 \\
\hline Luxembourg & 44712 & 61574 & 91131 \\
\hline Mexico & 12688 & 16720 & 27696 \\
\hline Netherlands & 30071 & 39108 & 43713 \\
\hline New Zealand & 18132 & 35078 & 35078 \\
\hline Norway & 29719 & 35541 & 36806 \\
\hline Poland & 6257 & 9462 & 10354 \\
\hline Portugal & 20150 & 33815 & 53085 \\
\hline Scotland & 27223 & 43363 & 43363 \\
\hline Slovak Republic & 5771 & 7309 & 9570 \\
\hline Spain & 29973 & 34890 & 43816 \\
\hline Sweden & 24488 & 28743 & 32956 \\
\hline Switzerland & 37544 & 49932 & 59667 \\
\hline Turkey & 12903 & 14580 & 16851 \\
\hline United States & 30339 & 43999 & 53563 \\
\hline Country mean & 24287 & 33336 & 40539 \\
\hline Argentina $^{1}$ & 6901 & 9670 & 11612 \\
\hline Brasil $^{1}$ & 8888 & 12005 & 13292 \\
\hline Chile & 11709 & 13671 & 18437 \\
\hline Egypt & 1046 & 2184 & $\mathrm{~m}$ \\
\hline India & 11735 & 19234 & 18163 \\
\hline Indonesia & 1002 & 1586 & 3022 \\
\hline Israel & 12331 & 15128 & 21054 \\
\hline Jamaica & 13354 & 16520 & 16520 \\
\hline Malaysia $^{1}$ & 9230 & 14490 & 17470 \\
\hline Paraguay ${ }^{1}$ & 7950 & 7950 & 7950 \\
\hline Peru $^{1}$ & 5669 & 5669 & 5669 \\
\hline Philippines ${ }^{1}$ & 9890 & 10916 & 11756 \\
\hline Sri Lanka & 3100 & 3945 & 3945 \\
\hline Thailand & 6048 & 14862 & 28345 \\
\hline Tunisia & 13120 & 13262 & 15067 \\
\hline Uruguay ${ }^{1}$ & 4850 & 5812 & 7017 \\
\hline
\end{tabular}

1 Dados referentes ao ano de 2002

Fonte: OECD (www.oecd.org/edu/eag2005). 
Ao considerar somente a média dos países pertencentes a OCDE, é possível avaliar que a remuneração docente no Brasil é precária, no entanto, ponderando os dados em relação a outros países da América Latina, a diferença salarial não é relativamente grande. Nesse caso, pesa a condição econômica do país, somada à elevada demanda por educação.

Os registros da OCDE de 2005 apresentam os salários anuais dos professores primários estatutários das instituições públicas no que se refere ao salário inicial, após 15 anos de experiência e no topo da carreira, também em dólares americanos PPP. Na tabela 4, a primeira coluna refere-se ao salário mínimo para a formação inicial, a segunda refere-se ao salário após 15 anos de experiência e a terceira ao chegar no último nível da carreira.

Os percentuais demonstram, mais uma vez, que o Brasil apresenta, remuneração muito aquém dos países componentes da OCDE, bem como entre os países parceiros, demonstrados nos quadros da Argentina e do Uruguai, ficando evidenciado na linha de corte que destaca a média de salários. Constata-se que somente a média é três vezes maior que o salário pago aos docentes de instituições públicas no Brasil, ou seja, a média de salário inicial de muitos países ainda é bem maior que o salário pago aos docentes brasileiros que se encontram em final de carreira.

Mas, a diferença é significativa quando observamos o salário inicial. Porém, quando analisamos o progresso da carreira, ou seja, após 15 anos de trabalho e o topo da carreira, não é possível visualizar grandes avanços em alguns países com salário inicial alto, como é o caso da Austrália, Dinamarca, Inglaterra, Finlândia, Nova Zelândia e Escócia, nos quais os salários dos docentes após 15 anos de serviço entram em processo de estagnação. Nesse sentido, percebe-se que o desprestigio da profissão não é uma prerrogativa de países menos desenvolvidos, mas, uma característica da profissão. Além disso, segundo Abdalla (2010, p. 80):

Todos sabemos que esta precarização pode ser traduzida pelos baixos salários e pelo desprestígio social reforçado pelo número elevado de trabalhadores de educação; nível de qualificação e atualização exigido; e feminização crescente e predominante no campo educacional. Fatores que determinam e condicionam, também, a intensificação dos processos de trabalho que os profissionais têm que enfrentar, assim como as situações de sofrimento e angústia por que passam.

\section{Condições de trabalho}

As condições de trabalho são de extrema relevância para o desenvolvimento do trabalho docente e para a garantia da valorização profissional. Conforme Caldas,

Entende-se por condições de trabalho o conjunto de recursos que possibilita uma melhor realização do trabalho educativo, e que envolve tanto a infraestrutura das escolas, os materiais didáticos disponíveis, quanto os serviços de apoio aos educadores e à escola (CALDAS, 2007, p.77).

As reformas educacionais postas nas últimas décadas trouxeram à tona uma nova reestruturação desse trabalho, entendido como resultante de novas formas de trabalho e novas políticas educacionais, revelando-se, conforme já indicado - significativamente precarizado -, também no que se refere às condições de trabalho. Nesse marco, o relatório Jacques Delors faz algumas sugestões, admitindo situações difíceis enfrentadas pelos docentes, conforme segue:

É preciso mais empenho em manter a motivação dos professores em situações difíceis e, para conservar no ensino os bons professores, oferecer-lhes condições de trabalho satisfatórias e remuneração comparável à das outras categorias de emprego que exigem um nível de formação equivalente. A concessão de incentivos especiais a professores que trabalham em zonas afastadas ou pouco convidativas é, evidentemente, necessária para os levar a permanecer nessas zonas, de modo que populações desfavorecidas não o fiquem ainda mais devido à falta de professores qualificados. Por mais desejável que seja a mobilidade geográfica, as colocações não deveriam ser decididas arbitrariamente pelas autoridades centrais. A mobilidade entre a profissão docente e outras profissões, durante períodos limitados, poderia ser incrementada com proveito (UNESC0, 2001, p.160) 
Os apontamentos do relatório indicam, mais uma vez, sugestões para motivar os docentes em suas funções, e a que mais chama a atenção é dar "incentivos" para atuarem em regiões com "populações desfavorecidas". Esses incentivos de ordem remuneratória são postos no sentido de "afagar" a necessidade de valorização e reconhecimento profissional dos professores. No entanto, não deixam de ser estímulos, que chamam a atenção para as dificuldades relacionadas ao acesso a regiões mais distantes e ao trabalho docente próximo às populações desfavorecidas. Porém, tais medidas não resolvem questão do salário propriamente dito, desvalorizado em relação a outras profissões. Cabe ressaltar que os incentivos não podem ser considerados um problema no aspecto da valorização, porque o verdadeiro problema reside nos baixos salários.

Somando-se à política de incentivos financeiros e de motivação profissional, foi possível visualizar na elaboração deste trabalho, alguns estudos sobre o docente e os mecanismos de avaliação e "controle" da sua atuação, com vistas ao ensino de qualidade. É o caso do uso dos resultados das avaliações nacionais de desempenho estudantil, que tem sido utilizado para a elaboração de ranking entre escolas de um mesmo sistema, de um mesmo país, ou entre países diferentes, sem considerar as desigualdades que permeiam cada contexto.

Na verdade, esses mecanismos são utilizados como dispositivos que têm como intuito principal responsabilizar os professores pelo baixo desempenho dos alunos, buscando desenvolver um sistema de accountability. Para Nigel Brooke (2006), essa responsabilização denominada por accountability, termo inglês que remete ao termo responsabilização, é evidente.

A lógica de estabelecer uma associação entre as atividades e os resultados da escola é clara: se os membros profissionais da comunidade escolar podem ser considerados responsáveis pela qualidade da experiência educativa sob seu controle direto, e se os resultados dessa experiência podem ser medidos objetivamente, então a avaliação do desempenho do aluno pode se tornar parte de um sistema de responsabilização que visa estimular a melhoria mediante a divulgação dos resultados da escola. (...) A resistência dos profissionais aos sistemas de responsabilização fundamenta-se no argumento de que a escola não pode ser responsabilizada por seus resultados se as secretarias não assegurarem as condições indispensáveis para um trabalho de qualidade. Parece inegável que qualquer sistema de responsabilização também precisa determinar o papel da entidade mantenedora e o nível de desempenho esperado (BROOKE, 2006, p. 398 -399).

\section{Hora-atividade}

Hora-atividade é o momento extraclasse, dentro da jornada de trabalho docente, considerado para planejamento, estudos e formação continuada dos professores. Nesse sentido, faz parte das condições de trabalho necessárias para os professores desenvolverem suas funções.

Embora, não trate especificamente da horaatividade, ou qualquer outro termo que signifique o conceito anteriormente descrito, é possível fazer uma breve relação com os dados da pesquisa Talis, no que tange as condições para realizar formação continuada ou desenvolvimento profissional, conforme documento do Instituto Nacional de Estudos e Pesquisas Anísio Teixeira (INEP) denominado "Pesquisa Talis - Nota para o Brasil" (OCDE, 2009b).

Depreende-se a partir dos dados constantes no documento mencionado, que: 1) $54,8 \%$ afirmaram que gostariam de ter tido mais oportunidades de se desenvolver profissionalmente; 2) $65,2 \%$ dos professores afirmam não ter pago nada pelo seu desenvolvimento profissional e uma proporção similar afirma ter sido liberada pelo empregador para poder fazer o desenvolvimento. 3) E entre os motivos de impedimento em relação ao treinamento profissional que os professores afirmaram necessitar, a razão mais comumente citada $(46,8 \%)$ foi o conflito de horários dos cursos com o trabalho. (OECD, 2009b)

Essas informações evidenciam que o período destinado para a formação continuada, ocorre em concomitância com os horários de trabalho, já que afirmam terem sido liberados pelo empregador para fazê-la, e quando não 
o fazem alegam conflito de horários entre o desenvolvimento profissional e horário de trabalho. Em sendo assim, percebe-se, a partir do relatado, que grande parte dos professores realiza cursos em tempo além da jornada contratada e remunerada.

\section{Jornada de Trabalho}

Para Marques e Abud (2008, p.79) "jornada de trabalho é período de tempo diário em que o empregado está à disposição do empregador em razão do contrato de trabalho".

Para efeito de compreensão de como se compõe uma jornada de trabalho, utilizaremos o conceito proposto pela Consolidação das Leis Trabalhistas (CLT), já que a jornada de trabalho do servidor público, que deveria estar explicitada nos artigos da CF 1988, que tratam da administração pública, apenas remete à legislação específica, no caso da educação, a LDB que não contempla esse aspecto. De acordo com o artigo 58 (CLT) a jornada de trabalho é composta de "duração normal de trabalho, para empregados em qualquer atividade privada, [que] não excederá de oito diárias, desde que não seja fixado expressamente outro limite". Também se aplica ao servidor público, profissional do magistério, por analogia, o artigo 58 A da CLT, segundo o qual, "considera-se trabalho em regime de tempo parcial aquele cuja duração não exceda 25 horas semanais" (BRASIL, 1943).

Os dados referentes à jornada de trabalho semanal dos professores podem ser observados na tabela 5. Como é possível notar, o Brasil apresenta jornada semanal acima do que está previsto na média em diversos países latinoamericanos, que é de 37 horas. No Brasil, mesmo coexistindo diferentes regimes de jornada de trabalho docente - como, por exemplo: 10, 20, 30 e 40 horas - de maneira geral, prevalece a jornada de 40 horas semanais, que nas redes públicas, correspondem a dois cargos ou padrões de trabalho, já que, em geral, estes são definidos por um período - matutino, vespertino, noturno - correspondente à jornada de estudo dos estudantes.
Tabela 5 - Horas semanais trabalhadas pelos professores

\begin{tabular}{|c|c|}
\hline País & Horas trabalhadas (Moda) \\
\hline Argentina & 20 \\
\hline Bolívia & 20 \\
\hline Brasil & 40 \\
\hline Chile & 40 \\
\hline Colômbia & 40 \\
\hline Costa Rica & 40 \\
\hline Equador & 40 \\
\hline El Salvador & 40 \\
\hline Guatemala & 25 \\
\hline Honduras & 25 \\
\hline México & 40 \\
\hline Nicaragua & 40 \\
\hline Paraguay & 40 \\
\hline Perú & 30 \\
\hline República Dominicana & 40 \\
\hline Uruguai & 20 \\
\hline Venezuela & 40 \\
\hline Média Ponderada & 37 \\
\hline
\end{tabular}

Notas: Dados de Bolivia, El Salvador e Guatemala são de 2004; do Chile, Honduras e Paraguai são de 2003. Nicarágua de 2001; e os demais países 2005. Fonte: La inversión educativa en América Latina y el Caribe: Las demandas de financiamiento y asignación de recursos. Autores: Alejandro Morduchowicz y Luisa Duro. 2007.

Desta forma cabe destacar que, nesse aspecto, verifica-se uma carga de trabalho intensa, que revela, mais uma vez, a precariedade das condições de trabalho e de vida desses professores, que poderão, dependendo do regime no qual foram contratados, trabalhar além das 40 horas semanais.

Um professor pode trabalhar em escolas particulares em um regime de 20 horas e mais um regime de 40 horas em instituições públicas. Pode ainda, trabalhar em dois regimes de 20 horas no serviço público, limite permitido constitucionalmente, e também 20 horas em uma escola privada, perfazendo assim, 60 horas semanais. Conforme destaca Caldas (2007, p.82): "Como consequência do rebaixamento dos salários, os professores vão se obrigando a aumentar o número de aulas dadas, triplicando a jornada de trabalho, atuando em diversas escolas". 


\section{Número de alunos por turma}

Discutir qualidade de educação é pensar situações de melhoria para atuação docente. A adequação do número de alunos por turma é uma evidente indicação.

A precarização na contratação de pessoal pode, também, ser verificada na superlotação das classes escolares, gerando comprometimento na qualidade do processo de ensino e aprendizagem, bem como sobrecarga que afeta diretamente a saúde do trabalhador docente.

Os dados da pesquisa Talis (tabela 6), no que se refere à relação entre quantidade de alunos e de pessoal nas escolas, informa o número médio de alunos por escola, a quantidade de professores em relação ao pessoal de apoio pedagógico, administrativo, ao tamanho médio da classe, destacando os dados referentes às escolas públicas.

\section{Tabela 6 - Características de pessoal e da percentagem de professores em escolas públicas}

\begin{tabular}{|c|c|c|c|c|c|c|c|c|c|c|}
\hline \multirow[b]{2}{*}{ Países } & \multicolumn{2}{|c|}{$\begin{array}{l}\text { Número de alunos } \\
\text { nas escolas }\end{array}$} & \multicolumn{2}{|c|}{$\begin{array}{l}\text { Proporção de } \\
\text { professores para } \\
\text { o número de } \\
\text { pessoal de apoio } \\
\text { pedagógico }\end{array}$} & \multicolumn{2}{|c|}{$\begin{array}{l}\text { Proporção de } \\
\text { professores com } \\
\text { o número de } \\
\text { funcionários de } \\
\text { administração ou } \\
\text { direção da escola }\end{array}$} & \multicolumn{2}{|c|}{$\begin{array}{l}0 \text { tamanho médio } \\
\text { da classe (ensino } \\
\text { secundário inferior } \\
\text { apenas) }\end{array}$} & \multicolumn{2}{|c|}{ Escolas públicas } \\
\hline & Média & (SE) & Média & (SE) & Média & (SE) & Média & (SE) & $\%$ & (SE) \\
\hline Australia & 754,0 & $(49,85)$ & 8,3 & $(0,61)$ & 5,5 & $(0,30)$ & 24,6 & 0,20 & 56,1 & $(1,80)$ \\
\hline Austria & 300,6 & $(9,84)$ & 24,1 & $(1,08)$ & 22,6 & $(0,82)$ & 21,1 & 0,14 & 89,1 & $(1,91)$ \\
\hline Belgium (FI.) & 491,2 & $(20,15)$ & 20,5 & $(1,63)$ & 11,7 & $(0,73)$ & 17,5 & 0,27 & 27,6 & $(1,39)$ \\
\hline Brasil & 601,2 & $(16,90)$ & 11,9 & $(0,72)$ & 6,9 & $(0,30)$ & 32,2 & 0,35 & 84,9 & $(0,81)$ \\
\hline Bulgaria & 314,7 & $(16,22)$ & 12,3 & $(1,31)$ & 4,8 & $(0,42)$ & 20,7 & 0,35 & 99,1 & $(0,54)$ \\
\hline Denmark & 340,4 & $(20,69)$ & 9,1 & $(0,97)$ & 7,5 & $(0,38)$ & 20,0 & 0,22 & 71,5 & $(1,65)$ \\
\hline Estonia & 361,3 & $(8,35)$ & 10,4 & $(0,69)$ & 7,6 & $(0,21)$ & 20,5 & 0,32 & 97,2 & $(1,49)$ \\
\hline Hungary & 394,3 & $(23,16)$ & 7,3 & $(0,69)$ & 8,3 & $(0,48)$ & 20,2 & 0,57 & 81,3 & $(4,03)$ \\
\hline Iceland & 266,5 & $(12,57)$ & 5,7 & $(0,60)$ & 6,3 & $(0,22)$ & 18,6 & 0,02 & 98,3 & $(0,06)$ \\
\hline Ireland & 454,5 & $(11,51)$ & 15,8 & $(1,06)$ & 11,1 & $(0,41)$ & 21,9 & 0,18 & 45,2 & $(2,54)$ \\
\hline Italy & 617,9 & $(30,35)$ & 20,4 & $(3,22)$ & 7,5 & $(0,32)$ & 21,3 & 0,16 & 96,1 & $(1,14)$ \\
\hline Korea & 646,6 & $(41,75)$ & 14,0 & $(1,12)$ & 4,9 & $(0,32)$ & 34,6 & 0,43 & 82,1 & $(2,91)$ \\
\hline Lithuania & 381,9 & $(10,11)$ & 16,7 & $(1,10)$ & 8,3 & $(0,23)$ & 19,3 & 0,24 & 98,5 & $(0,93)$ \\
\hline Malaysia & 1046,0 & $(25,94)$ & 12,4 & $(1,01)$ & 7,5 & $(0,45)$ & 34,9 & 0,28 & 98,8 & $(0,57)$ \\
\hline Malta & 495,8 & $(20,83)$ & 7,9 & $(0,74)$ & 8,7 & $(0,57)$ & 19,6 & 0,01 & 67,5 & $(0,16)$ \\
\hline Mexico & 436,0 & $(19,09)$ & 7,9 & $(0,68)$ & 5,0 & $(0,34)$ & 37,8 & 0,55 & 83,0 & $(1,20)$ \\
\hline Norway & 243,0 & $(10,11)$ & 7,0 & $(0,41)$ & 8,3 & $(0,31)$ & 21,4 & 0,29 & 96,3 & $(1,90)$ \\
\hline Poland & 242,2 & $(13,35)$ & 9,4 & $(0,56)$ & 9,0 & $(0,48)$ & 20,8 & 0,27 & 94,4 & $(1,48)$ \\
\hline Portugal & 800,8 & $(33,65)$ & 10,8 & $(1,64)$ & 10,5 & $(0,59)$ & 21,3 & 0,21 & 89,3 & $(0,73)$ \\
\hline Slovak Republic & 351,8 & $(14,52)$ & 14,3 & $(1,15)$ & 4,7 & $(0,17)$ & 21,1 & 0,26 & 87,8 & $(3,03)$ \\
\hline Slovenia & 377,1 & $(6,56)$ & 18,3 & $(1,16)$ & 7,8 & $(0,34)$ & 18,8 & 0,18 & 100,0 & $(0,00)$ \\
\hline Spain & 536,7 & $(25,78)$ & 19,0 & $(0,91)$ & 8,8 & $(0,68)$ & 21,7 & 0,26 & 75,6 & $(2,34)$ \\
\hline Turkey & 795,5 & $(53,98)$ & 22,2 & $(2,53)$ & 10,4 & $(0,49)$ & 31,3 & 0,75 & 92,5 & $(1,16)$ \\
\hline TALIS Média & 489,1 & $(5,21)$ & 13,3 & $(0,27)$ & 8,4 & $(0,09)$ & 23,5 & $(0,07)$ & 83,1 & $(0,37)$ \\
\hline
\end{tabular}

Fonte: OECD, TALIS Database. 
Como se pode notar, o Brasil é um dos países que possuem maior quantidade de alunos por sala de aula, ou seja, enquanto a média entre os países é de 23, no Brasil esse número salta para 32 alunos por sala de aula. Como os dados se referem a médias, pode-se inferir que existem turmas com números ainda mais elevados.

Os resultados do TALIS demonstram que, entre todos os países, menos práticas orientadas aos estudantes são utilizadas em turmas grandes. Isso sugere que salas de aula maiores limitam a possibilidade de dar atenção individual aos estudantes e, consequentemente, garantir melhoria no desempenho estudantil (OECD, 2009, p. 122).

Quanto aos demais dados, percebe-se ainda que o número médio de professores por pessoal de apoio pedagógico é de 11,9 e de professores por pessoal administrativo, 6,9 no Brasil, enquanto a média Talis é de 13,3 e 8,4, respectivamente. Em ambos os casos, o Brasil está abaixo da média.

Segundo pesquisa realizada por Carnoy, Gove e Marshall (2003) é possível perceber que, em comparação a Cuba, o número de alunos em sala de aula também é alto no Chile e no Brasil, conforme descreve a tabela 7 .

\section{Tabela 7 - Principais características das classes observadas}

\begin{tabular}{|c|c|c|c|c|c|c|c|}
\hline \multirow{2}{*}{$\begin{array}{l}\bar{\Phi} \\
: \frac{\pi}{\frac{\pi}{\hbar}} \\
>\end{array}$} & \multicolumn{3}{|c|}{$\begin{array}{c}\text { Comparação entre } \\
\text { países }\end{array}$} & \multicolumn{4}{|c|}{ Apenas escolas urbanas } \\
\hline & Brasil & Chile & Cuba & Brasil & $\begin{array}{l}\text { Chile } \\
\text { público }\end{array}$ & $\begin{array}{l}\text { Chile } \\
\text { particular }\end{array}$ & Cuba \\
\hline 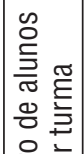 & 27,9 & 37,1 & 17,9 & 28,0 & 36,2 & 38,5 & 19,8 \\
\hline 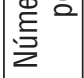 & & & & & & & \\
\hline
\end{tabular}

Fonte: As razões das diferenças de desempenho acadêmico na América Latina: dados qualitativos do Brasil, Chile e Cuba. Martin Carnoy; Amber K. Gove; Jeffery H. Marshall. Revista Brasileira de Estudos Pedagógicos, v.84, n² 206/207/208, p. 7-33, jan./ dez. 2003

Se considerarmos apenas a comparação entre esses países, veremos que o número de alunos aumenta em dez alunos por turma, a partir dos dados de Cuba, seguido pelo Brasil e depois o Chile.

\section{Regime de Contratação}

Considerando que o regime de contratação também faz parte das condições de trabalho do professor, as diferentes formas de contratação também causam impacto na qualidade do ensino, segundo dados da pesquisa Talis (2009).

Tabela 8 - Status do emprego

\begin{tabular}{|c|c|c|c|c|c|c|}
\hline \multirow[b]{2}{*}{ Países } & \multicolumn{2}{|c|}{$\begin{array}{c}\text { Empregado } \\
\text { permanentemente }\end{array}$} & \multicolumn{2}{|c|}{$\begin{array}{l}\text { Contrato a } \\
\text { prazo fixo: } \\
\text { Mais de um } \\
\text { ano escolar }\end{array}$} & \multicolumn{2}{|c|}{$\begin{array}{c}\text { Contrato a } \\
\text { termo: um } \\
\text { ano escolar ou } \\
\text { menos }\end{array}$} \\
\hline & $\%$ & (SE) & $\%$ & (SE) & $\%$ & (SE) \\
\hline Australia & 86,8 & $(1,00)$ & 4,3 & $(0,73)$ & 8,9 & $(0,71)$ \\
\hline Austria & 89,3 & $(0,64)$ & 2,0 & $(0,28)$ & 8,7 & $(0,55)$ \\
\hline Belgium & 80,7 & $(0,90)$ & 4,8 & $(0,41)$ & 14,6 & $(0,83)$ \\
\hline Brasil & 74,2 & $(1,46)$ & 7,1 & $(0,79)$ & 18,7 & $(1,41)$ \\
\hline Bulgaria & 84,6 & $(1,25)$ & 4,4 & $(0,67)$ & 11,0 & $(1,10)$ \\
\hline Denmark & 96,6 & $(0,63)$ & 0,3 & $(0,15)$ & 3,1 & $(0,62)$ \\
\hline Estonia & 84,2 & $(1,12)$ & 5,0 & $(0,46)$ & 10,8 & $(0,91)$ \\
\hline Hungary & 86,1 & $(1,75)$ & 2,9 & $(0,49)$ & 11,0 & $(1,52)$ \\
\hline Iceland & 74,6 & $(1,12)$ & 6,2 & $(0,67)$ & 19,2 & $(0,98)$ \\
\hline Ireland & 73,4 & $(1,10)$ & 7,8 & $(0,67)$ & 18,8 & $(1,00)$ \\
\hline Italy & 80,6 & $(0,85)$ & $\mathrm{a}$ & $\mathrm{a}$ & 19,4 & $(0,85)$ \\
\hline Korea & 95,6 & $(0,41)$ & 4,2 & $(0,42)$ & 0,2 & $(0,08)$ \\
\hline Lithuania & 92,4 & $(0,56)$ & 4,2 & $(0,40)$ & 3,4 & $(0,38)$ \\
\hline Malaysia & 97,8 & $(0,29)$ & 1,9 & $(0,33)$ & 0,4 & $(0,20)$ \\
\hline Malta & 96,3 & $(0,55)$ & 1,2 & $(0,34)$ & 2,5 & $(0,46)$ \\
\hline Mexico & 86,8 & $(1,88)$ & 5,0 & $(0,56)$ & 8,2 & $(1,74)$ \\
\hline Norway & 89,9 & $(0,88)$ & 1,8 & $(0,35)$ & 8,3 & $(0,80)$ \\
\hline Poland & 77,1 & $(1,11)$ & 5,1 & $(0,67)$ & 17,8 & $(0,93)$ \\
\hline Portugal & 67,6 & $(1,39)$ & 15,0 & $(0,88)$ & 17,4 & $(0,99)$ \\
\hline $\begin{array}{c}\text { Slovak } \\
\text { Republic }\end{array}$ & 82,1 & $(1,09)$ & 3,8 & $(0,48)$ & 14,1 & $(1,02)$ \\
\hline Slovenia & 82,8 & $(0,79)$ & 2,2 & $(0,34)$ & 15,0 & $(0,78)$ \\
\hline Spain & 75,6 & $(1,06)$ & 6,5 & $(0,41)$ & 17,9 & $(1,01)$ \\
\hline Turkey & 88,3 & $(1,32)$ & 4,6 & $(0,79)$ & 7,0 & $(0,95)$ \\
\hline $\begin{array}{l}\text { TALIS } \\
\text { Média }\end{array}$ & 84,5 & $(0,23)$ & 4,6 & $(0,11)$ & 11,1 & $(0,20)$ \\
\hline
\end{tabular}

Fonte: OECD, TALIS Database.

Os percentuais demonstram ainda que, entre os países pesquisados, o Brasil, situase entre os que possuem menos professores contratados de forma permanente, ou seja, via concurso público ou situação similar, com menor índice de contratação permanente encontram-se apenas Irlanda e Portugal. Tal situação revela a precariedade dos vínculos de trabalho que, pela falta de estabilidade, pode comprometer a aquisição de experiência e constituição de formação de equipe na escola, que são fatores que patrocinam a melhoria da qualidade do trabalho. 


\section{Conclusões}

A partir das análises realizadas é possível identificar certa uniformidade no âmbito da formação de professores entre todos os países pesquisados. A formação inicial dos docentes, em sua maioria, é de nível superior e a formação continuada também é uma política presente em todos os países. No entanto, é necessário avaliar a relevância dos cursos oferecidos tanto na formação inicial como na continuada em relação à qualidade do ensino.

As disparidades na remuneração chamam a atenção, uma vez que os professores latinoamericanos recebem, em média, três vezes menos que os professores de países pertencentes à OCDE. Entretanto, segundo a pesquisa Talis (OCDE, 2009), os professores situam-se entre os profissionais de menor salário em relação a outras profissões.

Em relação aos aspectos referentes às condições de trabalho, os dados não permitem conclusões sobre a questão da hora-atividade, já que a questão só foi analisada indiretamente. Justamente por não constar como item das pesquisas, pode-se deduzir que a garantia de horário para atividades extraclasse não constam como políticas prioritárias.

No entanto quando se trata de jornada de trabalho, percebe-se que os professores brasileiros apresentam uma intensa carga de trabalho, uma vez que a sua jornada, de 40 horas em média, ultrapassa a média dos países latinoamericanos, de 37 horas.

É possível observar ainda que o Brasil, em relação aos demais países, apresenta um elevado número de alunos por turma, o que mais uma vez aprofunda a precariedade das condições de trabalho e de ensino no sistema brasileiro.

E por fim, no que se refere ao regime de contratação, percebe-se que o Brasil é um dos países com menores índices de contratação permanente de professores, sendo que um pouco mais de $25 \%$ dos docentes são contratados temporariamente.

Assim, considerando a remuneração e a carga de trabalho, pode-se inferir que se apresenta uma precarização das condições de trabalho, essas que por sua vez encontram-se por legitimadas pelas políticas educacionais. Nesse sentido, o profissional docente enfrenta em seu trabalho contradições insustentáveis que de um lado valorizam a educação e o trabalho docente e, de outro, sobrecarregam e precarizam o trabalho dos profissionais.

A valorização do trabalho docente depende da confluência de três elementos: a existência de condições de trabalho adequadas, uma formação de qualidade e um sistema de avaliação que fortaleça a capacidade dos docentes em sua prática. Porém, são escassos os estímulos para que a carreira seja atrativa, no que se refere às condições de formação, trabalho e salário. E as tendências políticas não têm indicado mudanças nessa direção.

\section{Referências Bibliográficas:}

ABDALLA, M. F. B.; Trabalhadores da educação: políticas de prevenção e atendimento à saúde; Cadernos de Educação da CNTE, Brasília, n² 22, jan./jun. 2010.

BRASIL. Decreto-Lei $n^{\circ} 5.452$ de $1^{\circ}$ de maio de 1943. Consolidação das Leis do Trabalho (CLT). Disponível em: http://www. planalto.gov.br/ccivil/Decreto-Lei/Del5452.htm. Acesso em: 03 de março de 2010.

Constituição: República Federativa do Brasil de 1988. Brasília, DF: Senado Federal, 1988. Disponível em: http://www.planalto.gov.br/ccivil_03/constituicao/constitui\%C3\%A7ao.htm Acesso em: 03 de março de 2010.

. Lei n. 9394 de 20 de dezembro de 1996. Estabelece as Diretrizes e Bases da Educação Nacional (LDB). Diário Oficial da República Federativa do Brasil, Brasília, n. ${ }^{\circ}$ 2048, p.27833-27841, 23 dez. 1996. BROOKE, N.; O futuro das políticas de responsabilização educacional no Brasil. Cadernos de Pesquisa, v. 36, n. 128 , p. 377-401, maio/ago. 2006 
CALDAS, A. R. do; Desistência e Resistência no trabalho Docente: um estudo das professoras e professores do Ensino Fundamental da Rede Municipal de Educação de Curitiba. 173 f. Tese (Doutorado em Educação) - Setor de Educação, Universidade Federal do Paraná, Curitiba, 2007

CARNOY, M.; GOVE, A. K. ; MARSHALL, J. H.; As razões das diferenças de desempenho acadêmico na América Latina: dados qualitativos do Brasil, Chile e Cuba. Revista Brasileira de Estudos Pedagógicos, v.84, nº 206/207/208, p. 7-33, jan./ dez. 2003.

MARQUES, F.; ABUD, C. J.; Direito do Trabalho, $4^{a}$ ed. São Paulo: Atlas, 2008.

MORDUCHOWICZ, A.; DURO, L. La inversión educativa en América Latina y el Caribe. Las demandas de financiamiento y asignación de recursos. Buenos Aires: Unesco/IIPE, 2007, 61p. Disponível em: www. iipe-buenosaires.org.ar. Acesso em: 05/10/2010.

OCDE Education at a Glance. (2005) Disponível em: http://www.oecd.org/document/34/0,3343, en_2649_39263238_35289570_1_1_1_1,00.html. Acesso: 31/05/2010

TALIS: Teaching and Learning International Survey. (2009) Disponível em: .www.oecd.org / edu / talis Acesso: 31/05/2010.

Pesquisa Talis. Pesquisa com Diretores de Escolas e Professores do Ensino Fundamental de $5^{a}$ a $8^{a}$ série ou $6^{\circ}$ ao $9^{\circ}$ ano - Nota para o Brasil. (2009b). Disponível em: http://www.inep.gov.br/download/ imprensa/2009/internacional/Briefing_Talis_16-06-2009.pdf Acesso em 30/maio de 2010.

PINTO, J. M. R.; Remuneração adequada do professor: desafio à educação brasileira. Revista Retratos da Escola/ CNTE, Brasília, Vol. 3, n 4, jan./jun. 2009.

RODRIGUEZ, M. V.; VARGAS, M. B.; A formação dos professores na América Latina: um balanço dos debates dos fóruns internacionais 1966-2002; Políticas Educacionais e a formação de professores em tempos de globalização; Brasília: Líber Livro Editora, 2008.

UNESCO. International Standard Classification of Education - ISCED. 1997. Disponível em: http://www. uis.unesco.org/ev.php?ID=7433_201\&ID2=DO_TOPIC Acesso em 30/maio de 2010.

Educação: um tesouro a descobrir: Relatório para a UNESCO da Comissão Internacional sobre educação para o século XXI. Presidente: Jacques Delors. 5 ed. São Paulo: Cortez; Brasília, DF: MEC: UNESCO, 2001. 